\title{
Review
}

\section{Fasting, Nutrition and Weight Loss: An Approach to Refine Non-Alcoholic Fatty Liver Disease}

\author{
Galal A. Al-SAMHARI ${ }^{1}$, Gaber M. Al-MUSHIKI ${ }^{1}$, Rashi TAMrAKAR ${ }^{2}$, \\ Gibirima ABDULLAHI ${ }^{2}$, YUE-Dong LIN ${ }^{1}$ and XIAN-Yan TANG ${ }^{1, *}$ \\ ${ }^{1}$ School of Public Health, Guangxi Medical University, Guangxi Zhuang Autonomous Region, P.R. China \\ ${ }^{2}$ Internal Medicine, The First Affiliated Hospital of Guangxi Medical University, Nanning, P.R. China
}

(Received June 3, 2021)

\begin{abstract}
Summary Non-alcoholic fatty liver disease (NAFLD) is considered as one of the most common causes of chronic liver disease. It includes a group of conditions associated with fat deposition in liver cells. Also, NAFLD is strongly associated with obesity and insulin resistance (IR). Until now, there is no pharmacological treatment validated for this disease. Fasting, nutritional intervention, and weight loss can be considered the first line in treating hepatic steatosis. This review is based on the scientific evidence showing the results of these interventions in the past years. The results include fasting and nutritional support for NAFLD treatment in humans. In clinical trials and cohort studies, an increase in hepatic fat content was correlated with a weight loss of at least $7 \%$ and a diet resembling the Mediterranean diet (MD) improving hepatic biomarkers and histological regression of NAFLD. Fasting is a dietary approach known to improve the lipid profile in healthy and obese populations by decreasing overall cholesterol, triglycerides, LDL, and increasing HDL. Bariatric surgery helps improve liver fat content in patients with serious health problems due to overweight.
\end{abstract}

Key Words fasting, non-alcoholic fatty liver disease (NAFLD), nutrition, obesity, weight loss

Non-alcoholic fatty liver disease (NAFLD), also known as metabolic dysfunction-related fatty liver disease, is an increased fat accumulation in the liver, exceeding 5\% without any cause such as drinking alcohol, viral infection or any other liver disease etiology (1-3). It ranges from relatively benign hepatic steatosis to more severe non-alcoholic steatohepatitis (NASH), hepatic fibrosis, cirrhosis, liver failure, liver cancer, or even cardiovascular disease (4-8). It affects about $25 \%$ of the world's population and is the world's most widespread liver disease (9) with the prevalence of $24 \%, 25 \%$ and $30 \%$ in European, Italian and American citizens, respectively $(10,11)$, while the prevalence in Asia area ranges from $15 \%$ to $40 \%$ (12).

This disease is increasing among obese people and those with other metabolic syndromes (MetS) (13-16), with a prevalence of up to $80 \%$ in obese patients against only $16 \%$ in normal build people without any metabolic risk factor. Fatty liver disease correlates with body mass index (BMI), but it is more closely related to visceral fatness $(17,18)$. In addition, it is estimated that 25 to $75 \%$ of diabetic patients, according to the studies, have steatosis $(19,20)$. Almost three-quarters of older people with diabetes or obesity are believed to have NASH, with progressive fibrosis (14).

Considering that no known pharmacological treat-

\footnotetext{
*To whom correspondence should be addressed.
}

E-mail: tangxianyan0746@163.com ment has been validated till date as per the studies (21, 22 ), diet modification and weight loss have been put forward as the first line of action undertaken for NAFLD management. The studies have shown that a healthy diet and weight loss in the early stages of NAFLD could be sufficient to control disease progression $(23,24)$. The fasting regimen has been rising in popularity over the past decade as a treatment $(25,26)$. Thus, this review discusses the pathophysiology and nutritional implications including the benefits of fasting and nutritional support itself for the NAFLD treatment, as per the scientific results conducted in the past years.

\section{Pathophysiology and Nutritional Implications}

Hepatic steatosis is defined as intrahepatic fat of at least $5 \%$ of liver weight (27). The theory results from an increase in the flow of free fatty acids (FFA) in the liver (food intake, excessive fat storage, decreased mitochondrial beta-oxidation, decreased synthesis and secretion of lipoproteins) $(28,29)$. An excess of dietary fat or fatty acid (FA) originating from adipose tissue and exceeding the possibilities of catabolism by mitochondrial beta-oxidation or secretion of lipoproteins can lead to hepatic triglyceride development (30). Indeed, overtaking mitochondrial beta-oxidation catabolic capacities or lipoproteins' formation can contribute to this hepatic accumulation of triglycerides (31).

In obese subjects and diabetic patients, obesity may lead to insulin resistance (IR) and MetS (32). IR would 


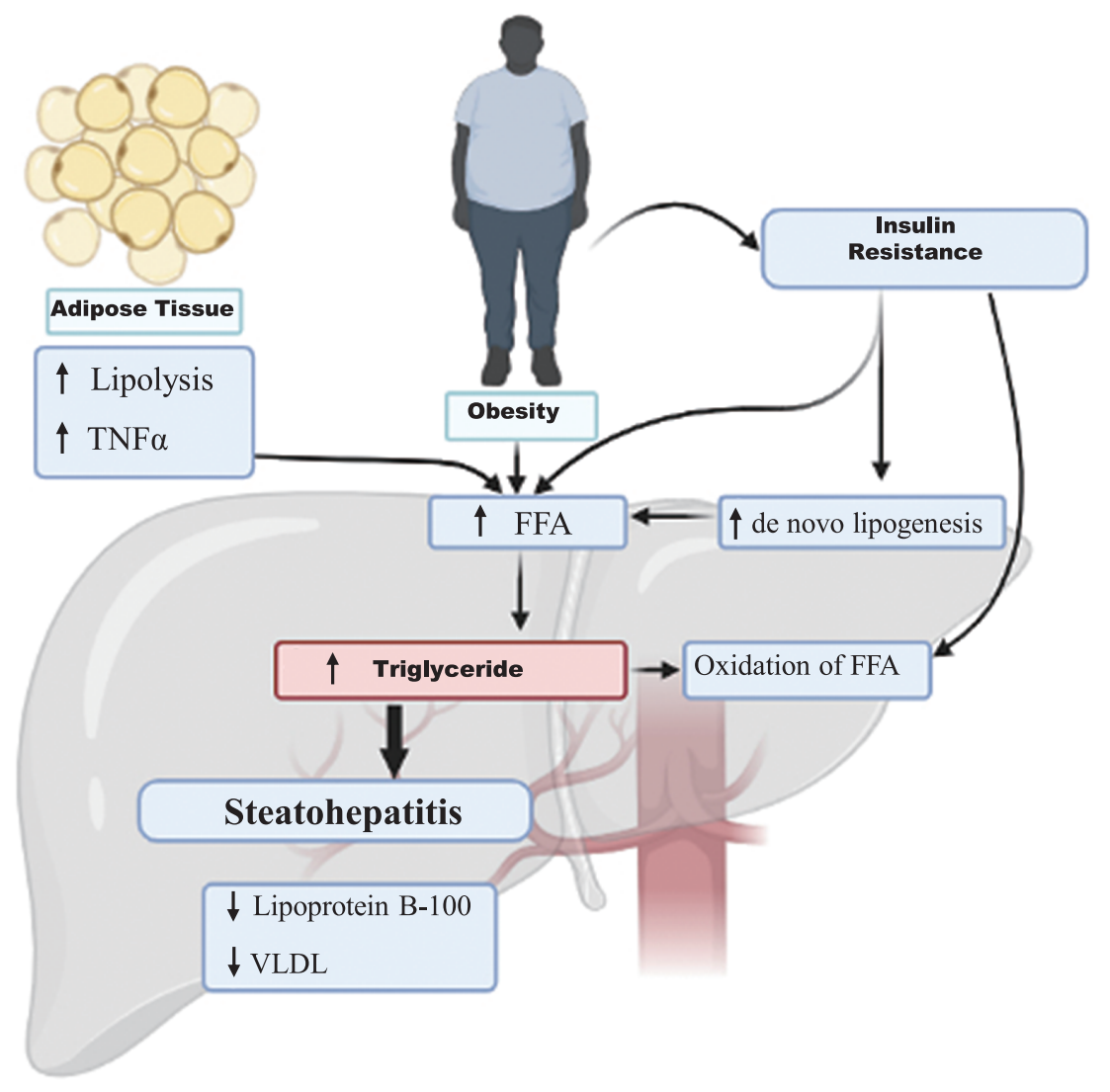

Fig. 1. Pathogenesis of steatohepatitis. FFA: free fatty acids, and VLDL: very low-density lipoproteins.

cause an increase in the flow of FA reaching the liver due to an increase in mass adipose tissue and a decrease in the antilipolytic effect of insulin. Export of FA in the form of VLDL is diminished and apolipoprotein B-100 is less synthesized due to the combined action of IR and TNF- $\alpha$ secreted by the adipose tissue. An excess of de novo synthesis of hepatic triglycerides can also explain steatosis (Fig. 1).

The progression to steatohepatitis would be linked to lipid peroxidation, oxidative stress, endotoxins and cytokines (especially TNF- $\alpha$ ) through hepatic cytotoxicity via different mechanisms $(33,34)$. Several studies show that a diet rich in saturated fatty acids and a lesser extent in polyunsaturated fatty acids (PUFA) from the omega-3 families quickly results in IR in the liver, muscle and adipose tissue (35-37). In humans, IR is most often associated with an increase in saturated membrane FA's contribution, especially with a long chain and a decrease in FA of the omega-3 families (38).

Cortez-Pinto et al., in their study showed that the patients with NASH had higher consumption of saturated fatty acids and cholesterol than the control subjects, leading to an excess of FFA and plasma triglycerides. The diet of patients with NASH was low in carbohydrates and fiber, high in fat and the ratio of omega-6/omega-3 was also higher (39).

A study from the Rotterdam highlighted animal proteins' role in NASH development in overweight or obese subjects. This study included 3,400 adults, with a mean age of 71 , including $70 \%$ overweight or obese. NASH was diagnosed by ultrasound examination in about $35 \%$ of patients. A high-protein diet, especially protein-based animals, was associated with NASH (odds ratio, OR: $1.50 ; 95 \% \mathrm{CI}=1.17-1.92)$. On the other hand, food rich in fruits and vegetables was protective (40). However, this result remains doubtful because most studies on the subject show a low-carbohydrate diet ( 25 to $45 \%$ of the energy intake daily) improving liver fat content (41).

In general, hepatic steatosis is an accumulation of triglycerides in the liver due to an increase in FFA flow to the liver by increasing food intake or decreased mitochondrial beta-oxidation lipoproteins. The hepatic steatosis in the IR and MetS resulted from increased adipose tissue mass and reduced insulin's antilipolytic effect. Steatohepatitis progression will be associated with lipid peroxidation, oxidative stress, endotoxins and cytokines by hepatic cytotoxicity via different methods.

\section{Nutritional Strategy in the Treatment of the NAFLD}

Fasting

Fasting is defined as a voluntary refrainment of some or all caloric foods and beverages for spiritual, therapeutic, or political reasons (42). Intermittent fasting (IF) regimes for a period lasting between $12-16 \mathrm{~h}$ for $3 \mathrm{wk}$ (43). IF is a short time of feeding originating in religious and spiritual traditions (44). The holy month of Ramadan, which is a time when millions of Muslims abstain from food and water consumption from sunrise 
(Sahur) to sunset (Iftar), lasts from 8-18 h according to the season and latitude. It's correlated with sleep schedule changes, physical activity, eating habits, and food intake quality, leading to metabolism changes $(45,46)$. Other forms of IF are also studied, such as alternating day fasting (ADF), whose basic principle includes an alternating day of regular food intake with a full day of fasting (47). This fasting form does not need water consumption limits because it doesn't have a religious connection $(48,49)$.

Previous studies have shown that $4-12$ wk of ADF administration can effectively decrease body weight and visceral fat mass (50-52). The beneficial findings for blood lipids (decrease in LDL cholesterol and triglycerides, increase in size particle of LDL) have been reported in addition to these favorable effects of ADF and Ramadan Fasting (RF) on body composition (5356).

In a randomized controlled trial, 271 NAFLD patients were randomized to the ADF group, time-restricted feeding group, or the control group and subjected to the respective diet for $12 \mathrm{wk}$. This study confirms that the ADF diet for NAFLD patients is healthy and tolerable and resulted in decreased bodyweight, fatty mass, and overall cholesterol and triglycerides. Besides, time-restricted feeding resulted in substantially lower BMI and cost-effective intervention in obese and NAFLD patients. The overall reduction of NAFLD patients' weight was $6.1 \%$ after 4 wk of dietary intervention and an additional 5.4\% after $12 \mathrm{wk}$. The ADF also benefits NAFLD patients since fat mass reduction was observed without improving fat-free mass (55).

Meta-analysis has shown that Ramadan's mean weight loss is $1.34 \mathrm{~kg}$ and that most weight has been recovered a couple of weeks after Ramadan (57). RF has shown a certain impact on the circulation of several biochemical markers correlated with vascular and metabolic disorders as a significant weight and body composition reductions (i.e., fat mass expressed as a percentage of weight $(\%)$ or absolute mass $(\mathrm{kg})$, and fatfree mass $(\mathrm{kg}))$ and significantly decreased $(p<0.05)$ in apoprotein B, lipoprotein (a) and LDL-C/HDL-C ratio, while total cholesterol, TG, LDL-C, HDL-C and fasting blood glucose did not change during Ramadan $(58,59)$. Visceral adiposity index (VAI) has proven to be an indicator of insulin sensitivity and has a good association with visceral adiposity. Increased VAI was related to cardiometabolic risk (60). Concerning NAFLD, VAI was confirmed as an accurate predictor for progressive liver histology more than other authenticated non-invasive scores (61).

In a recent study, 83 NAFLD (57 male and 26 female) patients were admitted during Ramadan, 42 fasting and 41 non-fasting patients from June 18 to July 17 in 2015 to assess the impact of RF on liver function; the Atherogenic Plasma Index (AIP) and VAI. This study found that the fasting group's liver enzyme concentrations were greater than the control group $(p=0.05$ and $p=$ 0.03 for SGPT and SGOT, respectively). Also, the total cholesterol, TG, and LDL were significantly reduced compared with before Ramadan values. The anthropometric parameters including weight, BMI, hip circumference, waist circumference, and waist-hip ratio showed significant differences in the RF group but not in another group. By the end of Ramadan, the mean values of VAI decreased and there was a significant improvement in the severity of NAFLD among the fasting groups $(p=0.02)(62)$.

In Islam; the pregnant or breastfeeding women who believe fasting for long hours will harm them or their babies (63), the elderly who cannot tolerate fasting, the sick who believe fasting will aggravate their condition, and patients with chronic medical condition such as diabetes are freed from performing this religious obligation $(64,65)$.

Regarding the risks and contraindications of fasting during Ramadan in NAFLD-related disease, in patients with diabetes, there isn't enough evidances to correlate $\mathrm{RF}$ to an increased or decreased risk of cardiovascular events. However, there were some indications that stroke risk might be increased (66). Diabetic individuals experience had a higher rate of hypoglycemia during RF $(67,68)$, and dehydration (69). On the other hand, several previous studies have found an increase in blood glucose levels during Ramadan $(45,70,71)$, but other studies revealed that RF had no elevation on blood glucose levels (72-74). Also, according to recent research, the risk of diabetic ketoacidosis does not rise during $\mathrm{RF}$ (75).

Overall, different fasting forms are cost-effective and are beneficial in reducing BMI and improving lipid profiles. VAI has proved to be a precise marker for indicating progressive liver histopathology and IF has improved NAFLD by reducing VAI mean values.

\section{Dietary support}

Low-restrictive personalized diets seem to be the most suitable in subjects with NAFLD. It showed that compliance is better with this type of diet compared to more severe and restrictive diets. Indeed, very low dietary prescriptions calories ( 800 or 1,000 kcal per day) or a little less restrictive (providing 1,200 to $1,500 \mathrm{kcal}$ ) can cause worsening of some liver damage. Some studies have shown that sudden weight loss can lead to worsening hepatic histological lesions. In a series of 41 morbidly obese subjects, weight loss obtained from a low-calorie diet resulted in significant improvement in fatty liver disease $(p<0.001)$, but inflammation or periportal fibrosis appeared in $24 \%$ of subjects emphasizing the risk imposed by a substantial restriction (76).

Several studies have enunciated on the role of PUFA in NAFLD evolution. PUFA would improve the NAFLD parameters via several mechanisms by reducing lipogenesis and inflammation mediators, such as IL-6 and TNF- $\alpha$ (77), would decrease liver fat content (78) and improve liver biochemical test and IR (79). However, there was significant heterogeneity between studies.

The patient with NAFLD should be encouraged to increase fiber intake by increasing the amount of fruits, vegetables, and whole grains and legumes in their diet (80). Research on the impacts of diets high in fiber and 
proteins in NAFLD is starting to be published; a prospective observational cohort investigated the association of a low-calorie diet rich in fiber and protein and the elastographic tests of liver fat content in 60 patients with hepatic steatosis (81). The results showed a significant reduction in hepatic fat content measured after $14 \mathrm{~d}$ of follow-up; a decrease in gamma-glutamyl transferase (GGT) and plasma lipids were also reported.

New evidence has accumulated in recent years suggesting that the Mediterranean diet (MD), rich in monoacid and PUFA, and aromatic compounds like polyphenols, might benefit NAFLD patients $(82,83)$.

A clinical trial was conducted to detect dietary differences in intestinal permeability in NAFLD patients with the Mediterranean or low-fat diet. Twelve patients underwent a 48-wk crossover diet for dietary therapy: 16-wk Mediterranean, 16-wk free wash-out diet and 16-wk low-fat diet. The validated method of urinary excretion of chromium-51 ethylene diamine tetra-acetate (51Cr-EDTA) excretion testing was used to assess intestinal permeability at the beginning and end of each dietary period. Excretion of 51Cr-EDTA is a strong predictor of intestinal mucosal severity to detect the alteration of intestinal permeability caused by diet in patients following an MD or low-fat diet with NAFLD. The finding after $16 \mathrm{wk}$ of a Mediterranean diet, there was a significant reduction in the mean of waist circumference $(-7.9 \pm 4.9 \mathrm{~cm}, p=0.001)$, body weight $(-5.3 \pm$ $4.1 \mathrm{~kg}, \quad p=0.003$ ), and transaminase levels (SGPT $-28.3 \pm 11.9 \mathrm{IU} / \mathrm{L}, p=0.0001$; SGOT $-6.4 \pm 56.3 \mathrm{IU} / \mathrm{L}$, $p=0.01)$. These advantages were sustained after $16 \mathrm{wk}$ of washout and $16 \mathrm{wk}$ of the low-fat diet, with no further improvements. Fourteen of 20 patients had intestinal permeability alteration at baseline (mean percentage retention of $51 \mathrm{Cr}$-EDTA $=5.4 \%$ ), but no significant changes in intestinal permeability were observed at the end of the $16 \mathrm{wk}$ of the low-fat or Mediterranean diet (84).

Increased cardiovascular risk in MetS patients and NAFLD has been associated with elevated fasting remnant cholesterol (REM-C) levels NAFLD (85). The objective of secondary analysis of the MEDIDIET study was to estimate the impact of various diets on the level of REM-C in MetS patients and the relation between NAFLD and REM-C. To measure the NAFLD score at baseline, 237 patients with MetS who received liver ultrasound were studied at 3- and 6-mo follow-up. The $\mathrm{MD}$, low glycemic index diet (LGID) or low glycemic index Mediterranean diet (LGIMD) is assigned randomly to the subjects. Study findings: REM-C levels in subjects with moderate or severe NAFLD were higher than in subjects with mild or absent NAFLD. After 3 and 6 mo, the three diets (MD, LGID and LGIMD) had a clear impact on decreasing the levels of REM-C. This effect was more significant among LGIMD in adherent subjects as opposed to the control group. Subjects with severe NAFLD have experienced a substantial rise in REM-C levels after 3 mo and a decline after 6 mo (85).

In a prospective study, fifty Caucasian patients were arbitrarily split into three categories (Groups A-C). The customized moderately hypocaloric MD was recommended for all patients in the A and B groups. In addition to the diet, Group B routinely obtained an antioxidant supplement for 6 mo. Group C had no medication of any kind. The study found that anthropometric parameters, lipid profile, and decreased hepatic fat accumulation and liver stiffness were improved by the MD alone (Group A) or in combination with the antioxidant complex (Group B), compared to the patients with no any medications (Group C). Moreover, the patients in Group B, whose diet included antioxidants, exhibited not only a substantial increase in insulin sensitivity, but also a considerable improvement in glucose tolerance. When compared to Group A patients, there was a more consistent drop in anthropometric indices. These findings established that the MD can enhance anthropometric measurements and lipid profile, as well as reduce hepatic fat buildup and stiffness. Furthermore, combining this dietary plan with antioxidant supplements may help to improve insulin sensitivity metrics. These findings suggest that antioxidant supplementation might be used as a coadjuvant treatment in NAFLD (11).

A randomized controlled trial of 56 NAFLD patients found a gap in the evidence about the influence of diets on hepatic steatosis. Patients were randomly assigned to one of two dietary intervention groups: low fat (LF) or moderate fat (MD). Dietary recommendations from the National Health and Medical Research Council and the American Heart Association were used to create the LF diet. The LF diet's target macronutrient energy contributions were $50 \%$ carbohydrates, $30 \%$ fat (with $10 \%$ of energy as saturated fat), and $20 \%$ protein. The MD was created by studying actual foods used in traditional Cretan meals and making changes to allow for standardization protein with the LF diet. The energy contributions from carbohydrates, fat, and protein were 40, 35-40, and $20 \%$ respectively. Related physical activity was assessed at the beginning and end of the study, and patients were advised to sustain the same usual physical activity during the test. Both $\mathrm{MD}$ and $\mathrm{LF}$ diets led to a similar degree of reduction (25-32\%) in hepatic steatosis and resolution of NAFLD. The results demonstrated that both MD and LF diets lead to a significant improvement in hepatic steatosis and measures of liver function (86). This finding complements the clear evidence of the effectiveness of diet-induced weight loss as the primary treatment for NAFLD.

A systematic review was done to evaluate the performance of various dietary patterns on hepatic endpoints of interest, including reduction of hepatic steatosis and fibrosis, weight loss, and metabolic endpoints. A total of 317 patients with a median age of 46 and BMI of 31.5; $64.3 \%$ were male and were represented from six different populations. The effects of the MD were examined in five of the six trials, whereas the sixth study looked at modified alternate-day calorie restriction. This study found that a statistically significant reduction in hepatic steatosis was founded in 3/5 MD, one IF, one low-carbohydrate, and $1 / 2$ low-fat diet interventions. There were considerable weight reductions on $3 / 5$ studies using 
MD, 1/2 low-fat interventions, and the one IF intervention. In two out of five trials evaluating MD, significant improvement in TG was observed. The preponderance of data favors MD-based therapies, although further randomized research is needed to evaluate NAFLD treatments' comparative efficacy (87).

In general, personalized diets are hepatic-friendly in NAFLD patients, in contrast to other ways that cause sudden weight loss, making the liver more vulnerable to severe damage. High-fiber and high-protein diet are suggested to improve hepatic-enzymes and lipid profiles. MD has beneficial outcomes in NAFLD subjects and MD consisting of PUFA with antioxidant supplements can actually reduce hepatic fats and refine IR, plasma lipids and anthropometric parameters.

Weight loss

Weight loss remains the proven therapy for NAFLD regression (4). The degree of histological change in the liver is directly proportional to the amount of weight loss. Seven percent and $9.3 \%$ of weight loss have improved histological lesions of steatosis and NASH confirmed via biopsy, respectively $(88,89)$. Recent research mentioned the effects of weight loss on liver disease biomarkers in patients with hepatic steatosis. Twenty-two randomized trials were analyzed ( $n=2,500$ patients) to study the effect of weight loss through dietary intervention, drug therapy or bariatric surgery, alone or a combination. The interventions on weight loss were significantly associated with an improvement in liver biomarkers, GPT and improved histological criteria for steatosis and steatohepatitis measured histologically or radiologically. Statistically, there are significant histological changes in liver fibrosis (90).

To explain how NAFLD's progression or remission is correlated with weight loss and lifestyle changes, a longitudinal cohort study reviewed the health check-up data for 1,421 subjects without liver disease besides NAFLD who had received at least two health check-ups between 2009 and 2018. Finally, they proved that weight change was related to NAFLD development and NAFLD remission (91).

In summary, weight loss and the associated interventions have markedly improved liver conditions structurally, histologically and biochemically. Weight loss of more than $7 \%$ and $9.3 \%$ have resulted in improving steatosis and NASH, respectively.

Place of bariatric surgery

Bariatric surgery involves a number of operations for patients who suffer from morbid or severe obesity with BMI of $>40 \mathrm{~kg} / \mathrm{m}^{2}$ or with BMI of at least $35 \mathrm{~kg} / \mathrm{m}^{2}$ with serious comorbid conditions. This type of surgery is performed by altering the levels of intestinal hormones responsible for hunger and satiety, leading to a new hormonal weight set point $(92,93)$.

Bariatric surgery in most patients reduced steatosis and steatohepatitis and was associated with improvement in both histologic and biochemical markers of NAFLD $(94,95)$, and in 30\% of patients, it resolved liver fibrosis. Compared with other procedures, Rouxen-Y gastric bypass surgery (RYGB) has a larger effect on NAFLD histology. A systematic review and metaanalysis of 21 studies $(n=2,374)$ by Fakhry et al. on NAFLD's improvement by bariatric surgery provided clear evidence that the histological and biochemical manifestations of NAFLD are greatly improved by bariatric surgery. More specifically, in 30\% of patients, bariatric surgery halted the progression or resolved liver fibrosis, which is superior to any other NASH procedure (96).

A prospective longitudinal study in 2014 compared the benefits of RYGB versus adjustable gastric band (AGB) on NAFLD. One thousand two hundred thirty-six obese patients were included, 681 in the RYGB and 555 in the AGB. The weight loss at $5 \mathrm{y}$ was $25.5 \pm 11.8 \%$ after RYGB against $21.4 \pm 12.7 \%$ after AGB $(p<0.001)$; all parameters of NAFLD improved after surgery $(p<$ 0.001) and even more significantly after RYGB (97).

In 2020, Cherla et al. published a work to study the long-term effects of RYGB and sleeve gastrectomy on NAFLD in 310 patients presented with NASH diagnosed intraoperatively by liver biopsy: $84 \%$ normalized their liver enzymes at the end of follow-up. There was no significant difference in patients' proportions with standardized values between RYGB and sleeve gastrectomy groups ( $84 \%$ vs. $82 \%, p=0.66$ ) (98).

The weight loss caused by bariatric surgery is usually accompanied by enzyme improvement and even hepatic histology. However, this improvement seems to vary depending on the type of intervention and severe liver damage. Interventions bypassing the small intestine's proximal part have a more marked metabolic effect, especially on glycemic regulation, which raises the question of the importance of their hepatic effect.

\section{Conclusion}

NAFLD is the hepatic manifestation of overweight and MetS. Till date, no pharmacological methods have been established, so lifestyle modifications remain the mainstay of NAFLD treatment. Studies have highlighted regimens like fasting and nutritional intervention as the treatment of NAFLD. These methods aid in reducing liver fat content, visceral obesity and also help to improve liver biomarkers and lipid profiles which prove to be effective in the management of NAFLD. Recently, MD has gained popularity among many and has found to be promising in dealing with various causes of NAFLD; it has resulted in better steatosis outcomes even without weight loss. A weight loss goal of $10 \%$ of the initial weight or the maximum weight is realistic and sufficient to improve hepatic histological lesions. However, it remains difficult in some patients to achieve optimal weight loss with diet modifications and physical exercises. In such a scenario, bariatric surgery plays a vital role in supporting weight loss in NAFLD patients.

\section{Future Directions}

Future researchers are suggested to use quantitative caloric consumption indicators, sleep length, energy expenditure and metabolic disorder signs, and provide more diverse studies. Further studies are needed to de- 
cide if the MD will potentially improve gut permeability in NAFLD patients. The beneficial effects of periodic fasting on fatty liver and glucose-lipid metabolism changes are still in their nascency, so additional experiments with a control group and follow-up for long-term adaptation are needed.

Until now, no precise data are available on the beneficial effects of Ramadan on NAFLD's severity; thus, further research is needed to be conducted before establishing any conclusion.

Additional studies on the improvement of liver functions after bariatric surgery are necessary to determine the association of steatosis and metabolic surgery in obese patients.

\section{Authorship}

Research conception and design: Xian-Yan Tang, Galal A. Al-Samhari; administrative support: Xian-Yan Tang; collection and assembly of the research materials and data: all authors; writing the manuscript: Xian-Yan Tang, Galal A. Al-Samhari, Gaber M. Al-Mushiki, Rashi Tamrakar; final approval of manuscript: All authors.

\section{Disclosure of state of COI}

The authors declare no conflict of interest.

\section{Funding statement}

This study was funded by the National Natural Science Foundation of China (Grant No. 81502890 and 81960615), and the China Medical Board (Grant No. 14-202 and 19-307). The sponsors had no role in study design, data collection, data analysis, or manuscript writing.

\section{Ethical consideration}

No known conflict of interest was associated with this publication. This manuscript was read and approved by all named authors, and there are no other persons who satisfied the criteria for authorship but are not listed. The order of authors listed in the manuscript has been approved by all the contributors. The authors have nothing to declare.

\section{REFERENCES}

1) Abd El-Kader SM, El-Den Ashmawy EM. 2015. Non-alcoholic fatty liver disease: The diagnosis and management. World J Hepatol 7: 846-858.

2) Piacentini M, Baiocchini A, Del Nonno F, Melino G, Barlev NA, Rossin F, D’Eletto M, Falasca L. 2018. Non-alcoholic fatty liver disease severity is modulated by transglutaminase type 2. Cell Death Dis 9: 257.

3) Zheng KI, Fan JG, Shi JP, Wong VW, Eslam M, George J, Zheng MH. 2020. From NAFLD to MAFLD: a "redefining" moment for fatty liver disease. Chin Med J (Engl) 133: 2271-2273.

4) Wang XJ, Malhi H. 2018. Nonalcoholic fatty liver disease. Ann Intern Med 169: ITC65-ITC80.

5) Chalasani N, Younossi Z, Lavine JE, Charlton M, Cusi K, Rinella M, Harrison SA, Brunt EM, Sanyal AJ. 2018. The diagnosis and management of nonalcoholic fatty liver disease: Practice guidance from the American
Association for the Study of Liver Diseases. Hepatology 67: 328-357.

6) Divella R, Mazzocca A, Daniele A, Sabba C, Paradiso A. 2019. Obesity, nonalcoholic fatty liver disease and adipocytokines network in promotion of cancer. Int J Biol Sci 15: 610-616.

7) Sarwar R, Pierce N, Koppe S. 2018. Obesity and nonalcoholic fatty liver disease: current perspectives. Diabetes Metab Syndr Obes 11: 533-542.

8) Dharmalingam M, Yamasandhi PG. 2018. Nonalcoholic fatty liver disease and type 2 diabetes mellitus. Indian J Endocrinol Metab 22: 421-428.

9) Younossi ZM, Koenig AB, Abdelatif D, Fazel Y, Henry L, Wymer M. 2016. Global epidemiology of nonalcoholic fatty liver disease-Meta-analytic assessment of prevalence, incidence, and outcomes. Hepatology 64: 73-84.

10) Goh GB, McCullough AJ. 2016. Natural history of nonalcoholic fatty liver disease. Dig Dis Sci 61: 1226-1233.

11) Abenavoli L, Greco M, Milic N, Accattato F, Foti D, Gulletta E, Luzza F. 2017. Effect of Mediterranean diet and antioxidant formulation in non-alcoholic fatty liver disease: A randomized study. Nutrients 9: 870.

12) Younossi Z, Tacke F, Arrese M, Chander Sharma B, Mostafa I, Bugianesi E, Wai-Sun Wong V, Yilmaz Y, George J, Fan J, Vos MB. 2019. Global perspectives on nonalcoholic fatty liver disease and nonalcoholic steatohepatitis. Hepatology 69: 2672-2682.

13) Brunt EM, Wong VW, Nobili V, Day CP, Sookoian S, Maher JJ, Bugianesi E, Sirlin CB, Neuschwander-Tetri BA, Rinella ME. 2015. Nonalcoholic fatty liver disease. Nat Rev Dis Primers 1: 15080.

14) Rinella ME. 2015. Nonalcoholic fatty liver disease: a systematic review. JAMA 313: 2263-2273.

15) Younossi ZM. 2019. Non-alcoholic fatty liver diseaseA global public health perspective. J Hepatol 70: 531544.

16) Singh S, Osna NA, Kharbanda KK. 2017. Treatment options for alcoholic and non-alcoholic fatty liver disease: A review. World J Gastroenterol 23: 6549-6570.

17) Lee HW, Kim KJ, Jung KS, Chon YE, Huh JH, Park KH, Chung JB, Kim CO, Han KH, Park JY. 2017. The relationship between visceral obesity and hepatic steatosis measured by controlled attenuation parameter. PLoS One 12: e0187066.

18) Yu AH, Duan-Mu YY, Zhang Y, Wang L, Guo Z, Yu YQ, Wang YS, Cheng XG. 2018. Correlation between nonalcoholic fatty liver disease and visceral adipose tissue in non-obese Chinese adults: A CT evaluation. Korean J Radiol 19: 923-929.

19) Tolman KG, Fonseca V, Dalpiaz A, Tan MH. 2007. Spectrum of liver disease in type 2 diabetes and management of patients with diabetes and liver disease. Diabetes Care 30: 734-743.

20) Portillo-Sanchez P, Bril F, Maximos M, Lomonaco R, Biernacki D, Orsak B, Subbarayan S, Webb A, Hecht J, Cusi K. 2015. High prevalence of nonalcoholic fatty liver disease in patients with type 2 diabetes mellitus and normal plasma aminotransferase levels. J Clin Endocrinol Metab 100: 2231-2238.

21) Recommendations of the Polish Group of Experts for Non-Alcoholic Fatty Liver Disease; Tomasiewicz K, Flisiak R, Halota W, Jaroszewicz J, Lebensztejn D, Lisik W, Malkowski P, Pawlowska M, Piekarska A, Simon K, Tronina O. 2018. Recommendations for the management of non-alcoholic fatty liver disease (NAFLD). Clin 
Exp Hepatol 4: 153-157.

22) Elhence A, Shalimar. 2020. Treatment of non-alcoholic fatty liver disease-Current perspectives. Indian J Gastroenterol 39: 22-31.

23) Berna G, Romero-Gomez M. 2020. The role of nutrition in non-alcoholic fatty liver disease: Pathophysiology and management. Liver Int 40 (Suppl 1): 102-108.

24) Perdomo CM, Fruhbeck G, Escalada J. 2019. Impact of nutritional changes on nonalcoholic fatty liver disease. Nutrients 11(3): 677.

25) Arnason TG, Bowen MW, Mansell KD. 2017. Effects of intermittent fasting on health markers in those with type 2 diabetes: A pilot study. World J Diabetes 8: 154 164.

26) Mattson MP, Longo VD, Harvie M. 2017. Impact of intermittent fasting on health and disease processes. Ageing Res Rev 39: 46-58.

27) Nassir F, Rector RS, Hammoud GM, Ibdah JA. 2015. Pathogenesis and prevention of hepatic steatosis. Gastroenterol Hepatol (NY) 11: 167-175.

28) Temple JL, Cordero P, Li J, Nguyen V, Oben JA. 2016. A guide to non-alcoholic fatty liver disease in childhood and adolescence. Int J Mol Sci 17: 947.

29) Oseini AM, Sanyal AJ. 2017. Therapies in non-alcoholic steatohepatitis (NASH). Liver Int 37 (Suppl 1): 97-103.

30) Wang J, He W, Tsai PJ, Chen PH, Ye M, Guo J, Su Z. 2020. Mutual interaction between endoplasmic reticulum and mitochondria in nonalcoholic fatty liver disease. Lipids Health Dis 19: 72.

31) Mota M, Banini BA, Cazanave SC, Sanyal AJ. 2016. Molecular mechanisms of lipotoxicity and glucotoxicity in nonalcoholic fatty liver disease. Metabolism 65: 1049-1061.

32) Kupcova V, Fedelesova M, Bulas J, Kozmonova P, Turecky L. 2019. Overview of the pathogenesis, genetic, and non-invasive clinical, biochemical, and scoring methods in the assessment of NAFLD. Int J Environ Res Public Health 16: 3750.

33) Takaki A, Kawai D, Yamamoto K. 2013. Multiple hits, including oxidative stress, as pathogenesis and treatment target in non-alcoholic steatohepatitis (NASH). Int J Mol Sci 14: 20704-20728.

34) Li S, Hong M, Tan HY, Wang N, Feng Y. 2016. Insights into the role and interdependence of oxidative stress and inflammation in liver diseases. Oxid Med Cell Longev 2016: 4234061.

35) Baynes HW, Mideksa S, Ambachew S. 2018. The role of polyunsaturated fatty acids (n-3 PUFAs) on the pancreatic beta-cells and insulin action. Adipocyte 7: 81-87.

36) Sears B, Perry M. 2015. The role of fatty acids in insulin resistance. Lipids Health Dis 14: 121.

37) Dangardt F, Chen Y, Gronowitz E, Dahlgren J, Friberg P, Strandvik B. 2012. High physiological omega-3 fatty acid supplementation affects muscle fatty acid composition and glucose and insulin homeostasis in obese adolescents. J Nutr Metab 2012: 395757.

38) Czumaj A, Sledzinski T. 2020. Biological role of unsaturated fatty acid desaturases in health and disease. Nutrients 12: 356.

39) Cortez-Pinto H, Jesus L, Barros H, Lopes C, Moura MC, Camilo ME. 2006. How different is the dietary pattern in non-alcoholic steatohepatitis patients? Clin Nutr 25: 816-823.

40) Alferink LJ, Kiefte-de Jong JC, Erler NS, Veldt BJ, Schoufour JD, de Knegt RJ, Ikram MA, Metselaar HJ, Janssen
H, Franco OH, Darwish Murad S. 2019. Association of dietary macronutrient composition and non-alcoholic fatty liver disease in an ageing population: the Rotterdam Study. Gut 68: 1088-1098.

41) Haghighatdoost F, Salehi-Abargouei A, Surkan PJ, Azadbakht L. 2016. The effects of low carbohydrate diets on liver function tests in nonalcoholic fatty liver disease: A systematic review and meta-analysis of clinical trials. J Res Med Sci 21: 53.

42) Fredricks R. 2012. Fasting: An Exceptional Human Experience. AuthorHouse, San Jose, California.

43) Patterson RE, Laughlin GA, LaCroix AZ, Hartman SJ, Natarajan L, Senger CM, Martinez ME, Villasenor A, Sears DD, Marinac CR, Gallo LC. 2015. Intermittent fasting and human metabolic health. J Acad Nutr Diet 115: 1203-1212.

44) Patterson RE, Sears DD. 2017. Metabolic effects of intermittent fasting. Annu Rev Nutr 37: 371-393.

45) Celik A, Saricicek E, Saricicek V, Sahin E, Ozdemir G, Bozkurt S, Okumus M, Sucakli MH, Cikim G, Coskun Y, Deniz MS, Dogan E, Kilinc M. 2014. Effect of Ramadan fasting on serum concentration of apelin-13 and new obesity indices in healthy adult men. Med Sci Monit 20: 337-342.

46) Yousefi B, Faghfoori Z, Samadi N, Karami H, Ahmadi Y, Badalzadeh R, Shafiei-Irannejad V, Majidinia M, Ghavimi H, Jabbarpour M. 2014. The effects of Ramadan fasting on endothelial function in patients with cardiovascular diseases. Eur J Clin Nutr 68: 835-839.

47) Longo VD, Mattson MP. 2014. Fasting: molecular mechanisms and clinical applications. Cell Metab 19: 181192.

48) Klempel MC, Kroeger CM, Varady KA. 2013. Alternate day fasting increases LDL particle size independently of dietary fat content in obese humans. Eur J Clin Nutr 67: 783-785.

49) Trepanowski JF, Kroeger CM, Barnosky A, Klempel MC, Bhutani S, Hoddy KK, Gabel K, Freels S, Rigdon J, Rood J, Ravussin E, Varady KA. 2017. Effect of alternate-day fasting on weight loss, weight maintenance, and cardioprotection among metabolically healthy obese adults: A randomized clinical trial. JAMA Intern Med 177: 930938.

50) Catenacci VA, Pan Z, Ostendorf D, Brannon S, Gozansky WS, Mattson MP, Martin B, MacLean PS, Melanson EL, Troy Donahoo W. 2016. A randomized pilot study comparing zero-calorie alternate-day fasting to daily caloric restriction in adults with obesity. Obesity (Silver Spring) 24: 1874-1883.

51) Klempel MC, Bhutani S, Fitzgibbon M, Freels S, Varady KA. 2010. Dietary and physical activity adaptations to alternate day modified fasting: implications for optimal weight loss. Nutr J 9: 35.

52) Johari MI, Yusoff K, Haron J, Nadarajan C, Ibrahim KN, Wong MS, Hafidz MIA, Chua BE, Hamid N, Arifin WN, Ma ZF, Lee YY. 2019. A randomised controlled trial on the effectiveness and adherence of modified alternateday calorie restriction in improving activity of non-alcoholic fatty liver disease. Sci Rep 9: 11232.

53) Varady KA, Bhutani S, Klempel MC, Kroeger CM, Trepanowski JF, Haus JM, Hoddy KK, Calvo Y. 2013. Alternate day fasting for weight loss in normal weight and overweight subjects: a randomized controlled trial. Nutr J 12: 146.

54) Klempel MC, Kroeger CM, Norkeviciute E, Goslawski M, 
Phillips SA, Varady KA. 2013. Benefit of a low-fat over high-fat diet on vascular health during alternate day fasting. Nutr Diabetes 3: e71.

55) Cai H, Qin YL, Shi ZY, Chen JH, Zeng MJ, Zhou W, Chen RQ, Chen ZY. 2019. Effects of alternate-day fasting on body weight and dyslipidaemia in patients with nonalcoholic fatty liver disease: a randomised controlled trial. BMC Gastroenterol 19: 219.

56) Tendler D, Lin S, Yancy WS Jr, Mavropoulos J, Sylvestre P, Rockey DC, Westman EC. 2007. The effect of a lowcarbohydrate, ketogenic diet on nonalcoholic fatty liver disease: a pilot study. Dig Dis Sci 52: 589-593.

57) Fernando HA, Zibellini J, Harris RA, Seimon RV, Sainsbury A. 2019. Effect of Ramadan fasting on weight and body composition in healthy non-athlete adults: A systematic review and meta-analysis. Nutrients 11: 478.

58) Sarraf-Zadegan N, Atashi M, Naderi GA, Baghai AM, Asgary S, Fatehifar MR, Samarian H, Zarei M. 2000. The effect of fasting in Ramadan on the values and interrelations between biochemical, coagulation and hematological factors. Ann Saudi Med 20: 377-381.

59) Mazidi M, Rezaie P, Karimi E, Nematy M. 2014. Effects of Ramadan fasting on lipid profile: A narrative review. J Fasting Health 2: 57-61.

60) Du T, Sun X, Huo R, Yu X. 2014. Visceral adiposity index, hypertriglyceridemic waist and risk of diabetes: the China Health and Nutrition Survey 2009. Int J Obes (Lond) 38: 840-847.

61) Amato MC, Giordano C. 2014. Visceral adiposity index: an indicator of adipose tissue dysfunction. Int J Endocrinol 2014: 730827.

62) Ebrahimi S, Gargari BP, Aliasghari F, Asjodi F, Izadi A. 2020. Ramadan fasting improves liver function and total cholesterol in patients with nonalcoholic fatty liver disease. Int J Vitam Nutr Res 90: 95-102.

63) Joosoph J, Abu J, Yu SL. 2004. A survey of fasting during pregnancy. Singapore Med J 45: 583-586.

64) Bragazzi NL, Briki W, Khabbache H, Rammouz I, Mnadla S, Demaj T, Zouhir M. 2015. Ramadan fasting and infectious diseases: a systematic review. J Infect Dev Ctries 9: 1186-1194.

65) Rispler-Chaim V. 2007. People with disabilities and the performance of religious duties. In: Disability in Islamic Law. International Library of Ethics, Law, and the New Medicine, p 19-39. Springer, Dordrecht, Netherlands.

66) Almulhem M, Susarla R, Alabdulaali L, Khunti K, Karamat MA, Rasiah T, Tahrani AA, Hanif W, Nirantharakumar K. 2020. The effect of Ramadan fasting on cardiovascular events and risk factors in patients with type 2 diabetes: A systematic review. Diabetes Res Clin Pract 159: 107918.

67) AlKhaldi YM, AlKhaldi AY, AlQahtani AS, Al-Shahrani BS, Meshawi EA, Albishri BM. 2019. Incidence of hypoglycemia and its risk factors among diabetics during Ramadan in Abha city, Aseer Region, KSA. J Family Med Prim Care 8: 2793-2798.

68) Tourkmani AM, Alharbi TJ, Rsheed AMB, AlRasheed AN, AlBattal SM, Abdelhay O, Hassali MA, Alrasheedy AA, Al Harbi NG, Alqahtani A. 2018. Hypoglycemia in type 2 diabetes mellitus patients: A review article. Diabetes Metab Syndr 12: 791-794.

69) Cherif A, Roelands B, Meeusen R, Chamari K. 2016. Effects of intermittent fasting, caloric restriction, and Ramadan intermittent fasting on cognitive performance at rest and during exercise in adults. Sports Med 46:
$35-47$.

70) Bahijri S, Borai A, Ajabnoor G, Abdul Khaliq A, AlQassas I, Al-Shehri D, Chrousos G. 2013. Relative metabolic stability, but disrupted circadian cortisol secretion during the fasting month of Ramadan. PLoS One 8: e60917.

71) Benaji B, Mounib N, Roky R, Aadil N, Houti IE, Moussamih S, Maliki S, Gressier B, El Ghomari H. 2006. Diabetes and Ramadan: review of the literature. Diabetes Res Clin Pract 73: 117-125.

72) Trepanowski JF, Bloomer RJ. 2010. The impact of religious fasting on human health. Nutr J 9: 57.

73) Aziz KM. 2013. Effect of fasting ramadan in diabetes control status - application of extensive diabetes education, serum creatinine with $\mathrm{HbAlc}$ statistical ANOVA and regression models to prevent hypoglycemia. Recent Pat Endocr Metab Immune Drug Discov 7: 233-251.

74) Karatoprak C, Yolbas S, Cakirca M, Cinar A, Zorlu M, Kiskac M, Cikrikcioglu MA, Erkoc R, Tasan E. 2013. The effects of long term fasting in Ramadan on glucose regulation in type 2 diabetes mellitus. Eur Rev Med Pharmacol Sci 17: 2512-2516.

75) Beshyah SA, Chowdhury TA, Ghouri N, Lakhdar AA. 2019. Risk of diabetic ketoacidosis during Ramadan fasting: A critical reappraisal. Diabetes Res Clin Pract 151: 290-298.

76) Andersen T, Gluud C, Franzmann MB, Christoffersen P. 1991. Hepatic effects of dietary weight loss in morbidly obese subjects. J Hepatol 12: 224-229.

77) Di Minno MN, Russolillo A, Lupoli R, Ambrosino P, Di Minno A, Tarantino G. 2012. Omega-3 fatty acids for the treatment of non-alcoholic fatty liver disease. World J Gastroenterol 18: 5839-5847.

78) Parker HM, Johnson NA, Burdon CA, Cohn JS, O'Connor HT, George J. 2012. Omega-3 supplementation and non-alcoholic fatty liver disease: a systematic review and meta-analysis. J Hepatol 56: 944-951.

79) Yan JH, Guan BJ, Gao HY, Peng XE. 2018. Omega-3 polyunsaturated fatty acid supplementation and nonalcoholic fatty liver disease: A meta-analysis of randomized controlled trials. Medicine (Baltimore) 97: e12271.

80) Hydes TJ, Ravi S, Loomba R, Gray ME. 2020. Evidencebased clinical advice for nutrition and dietary weight loss strategies for the management of NAFLD and NASH. Clin Mol Hepatol 26: 383-400.

81) Arslanow A, Teutsch M, Walle H, Grunhage F, Lammert F, Stokes CS. 2016. Short-term hypocaloric high-fiber and high-protein diet improves hepatic steatosis assessed by controlled attenuation parameter. Clin Transl Gastroenterol 7: e176.

82) Anania C, Perla FM, Olivero F, Pacifico L, Chiesa C. 2018. Mediterranean diet and nonalcoholic fatty liver disease. World J Gastroenterol 24: 2083-2094.

83) Ryan MC, Itsiopoulos C, Thodis T, Ward G, Trost N, Hofferberth S, O'Dea K, Desmond PV, Johnson NA, Wilson AM. 2013. The Mediterranean diet improves hepatic steatosis and insulin sensitivity in individuals with non-alcoholic fatty liver disease. J Hepatol 59: 138-143.

84) Biolato M, Manca F, Marrone G, Cefalo C, Racco S, Miggiano GA, Valenza V, Gasbarrini A, Miele L, Grieco A. 2019. Intestinal permeability after Mediterranean diet and low-fat diet in non-alcoholic fatty liver disease. World J Gastroenterol 25: 509-520.

85) Campanella A, Iacovazzi PA, Misciagna G, Bonfiglio C, Mirizzi A, Franco I, Bianco A, Sorino P, Caruso MG, Cis- 
ternino AM, Buongiorno C, Liuzzi R, Osella AR. 2020. The effect of three Mediterranean diets on remnant cholesterol and non-alcoholic fatty liver disease: A secondary analysis. Nutrients 12: 1674.

86) Properzi C, O'Sullivan TA, Sherriff JL, Ching HL, Jeffrey GP, Buckley RF, Tibballs J, MacQuillan GC, Garas G, Adams LA. 2018. Ad libitum Mediterranean and lowfat diets both significantly reduce hepatic steatosis: A randomized controlled trial. Hepatology 68: 17411754.

87) Saeed N, Nadeau B, Shannon C, Tincopa M. 2019. Evaluation of dietary approaches for the treatment of non-alcoholic fatty liver disease: A systematic review. Nutrients 11: 3064.

88) Musso G, Cassader M, Rosina F, Gambino R. 2012. Impact of current treatments on liver disease, glucose metabolism and cardiovascular risk in non-alcoholic fatty liver disease (NAFLD): a systematic review and meta-analysis of randomised trials. Diabetologia 55: 885-904.

89) Vilar-Gomez E, Martinez-Perez Y, Calzadilla-Bertot L, Torres-Gonzalez A, Gra-Oramas B, Gonzalez-Fabian L, Friedman SL, Diago M, Romero-Gomez M. 2015. Weight loss through lifestyle modification significantly reduces features of nonalcoholic steatohepatitis. Gastroenterology 149: 367-378 e365; quiz e314-365.

90) Koutoukidis DA, Astbury NM, Tudor KE, Morris E, Henry JA, Noreik M, Jebb SA, Aveyard P. 2019. Association of weight loss interventions with changes in biomarkers of nonalcoholic fatty liver disease: A systematic review and meta-analysis. JAMA Intern Med 179: 1262-1271.

91) Yoshioka N, Ishigami M, Watanabe Y, Sumi H, Doisaki M, Yamaguchi T, Ito T, Ishizu Y, Kuzuya T, Honda T, Ishikawa T, Haruta JI, Fujishiro M. 2020. Effect of weight change and lifestyle modifications on the development or remission of nonalcoholic fatty liver disease: sexspecific analysis. Sci Rep 10: 481.

92) Pucci A, Batterham RL. 2019. Mechanisms underlying the weight loss effects of RYGB and SG: similar, yet different. J Endocrinol Invest 42: 117-128.

93) Wolfe BM, Kvach E, Eckel RH. 2016. Treatment of obesity: Weight loss and bariatric surgery. Circ Res 118: 1844-1855.

94) Mummadi RR, Kasturi KS, Chennareddygari S, Sood GK. 2008. Effect of bariatric surgery on nonalcoholic fatty liver disease: systematic review and meta-analysis. Clin Gastroenterol Hepatol 6: 1396-1402.

95) Bower G, Toma T, Harling L, Jiao LR, Efthimiou E, Darzi A, Athanasiou T, Ashrafian H. 2015. Bariatric surgery and non-alcoholic fatty liver disease: a systematic review of liver biochemistry and histology. Obes Surg 25: 2280-2289.

96) Fakhry TK, Mhaskar R, Schwitalla T, Muradova E, Gonzalvo JP, Murr MM. 2019. Bariatric surgery improves nonalcoholic fatty liver disease: a contemporary systematic review and meta-analysis. Surg Obes Relat Dis 15 : 502-511.

97) Caiazzo R, Lassailly G, Leteurtre E, Baud G, Verkindt H, Raverdy V, Buob D, Pigeyre M, Mathurin P, Pattou F. 2014. Roux-en-Y gastric bypass versus adjustable gastric banding to reduce nonalcoholic fatty liver disease: a 5-year controlled longitudinal study. Ann Surg 260: 893-898; discussion 898-899.

98) Cherla DV, Rodriguez NA, Vangoitsenhoven R, Singh T, Mehta N, McCullough AJ, Brethauer SA, Schauer PR, Aminian A. 2020. Impact of sleeve gastrectomy and Roux-en-Y gastric bypass on biopsy-proven non-alcoholic fatty liver disease. Surg Endosc 34: 2266-2272. 